\title{
Rapid assessment of rest myocardial ischaemia in the Chest Pain Unit
}

\author{
Jader C. de Azevedo - Gustavo B. Barbirato • Renata C. Félix • Patricia L. Correa • \\ André Volschan • Cláudio Feldman • José Feldman • Hans F. Dohmann • Cláudio T. Mesquita
}

Received: 5 December 2008 / Accepted: 24 February 2009 /Published online: 19 March 2009

(C) Springer-Verlag 2009

A 76-year-old man with a history of coronary bypass graft surgery presented to the Chest Pain Unit with chest discomfort.

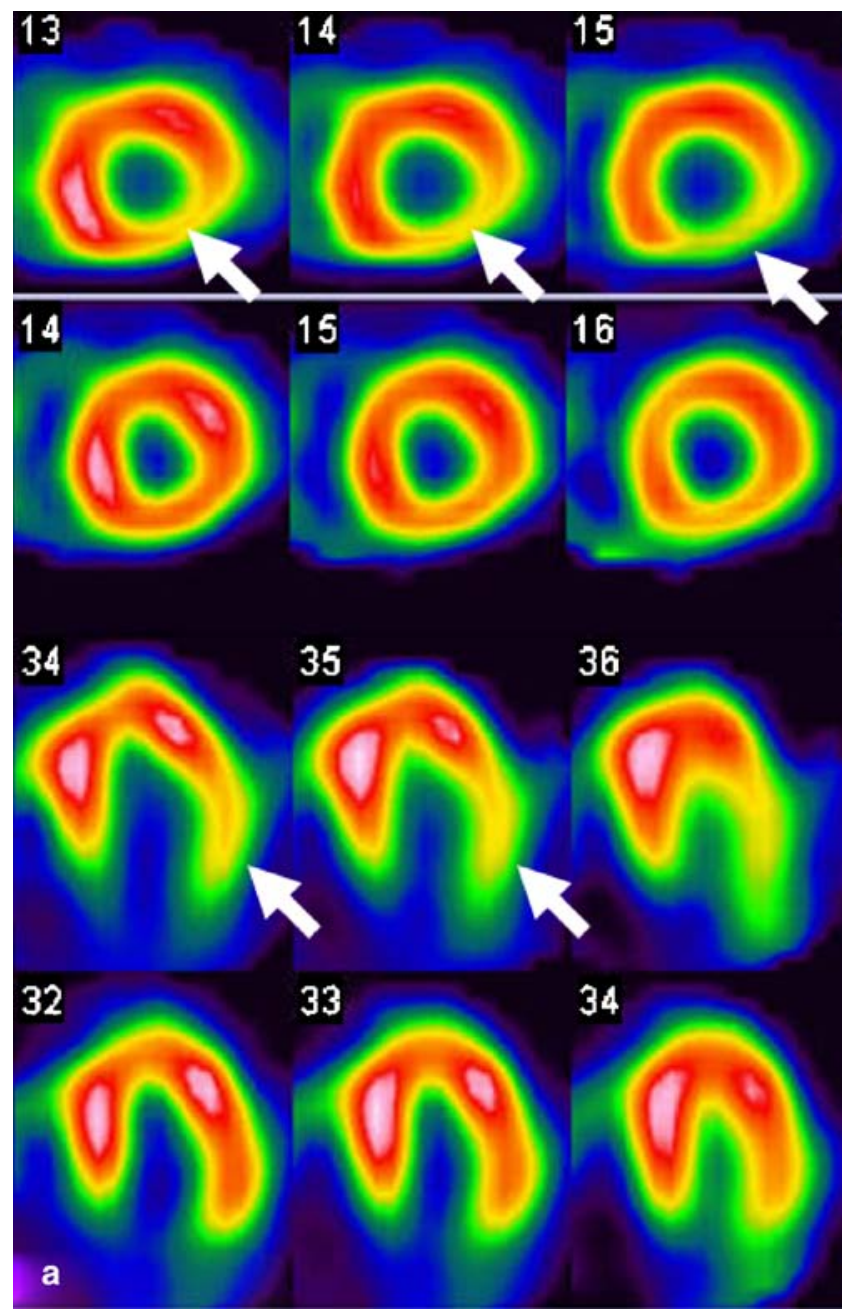

J. C. de Azevedo $(\bowtie) \cdot$ G. B. Barbirato $\cdot$ R. C. Félix $\cdot$

P. L. Correa $\cdot$ A. Volschan $\cdot$ C. Feldman $\cdot$ J. Feldman •

H. F. Dohmann $\cdot$ C. T. Mesquita

Hospital Pró-Cardíaco, Rio de Janeiro, Brazil

e-mail: jadercazevedo@gmail.com
He underwent myocardial perfusion imaging (MPI) with ${ }^{99 m} \mathrm{Tc}$-sestamibi. Immediately after acquisition of the rest scan he developed a new chest pain episode and received an additional tracer injection. The new images showed hypoperfusion in the inferior and inferolateral walls that were not observed in the previous rest scan images (a arrows). A coronary angiogram revealed subtotal proximal occlusion of a saphenous vein graft to the right coronary artery (b arrow) which was submitted to successful stent implantation.

Acute coronary syndrome results from the combination of intermittent thrombotic occlusion and vasoconstriction resulting in markedly decreased regional myocardial perfusion [1]. Abnormal rest MPI in patients with acute chest pain is highly associated with acute myocardial infarction or the need for subsequent coronary revascularization [2]. These images demonstrate the exquisite sensitivity of MPI to changes in rest myocardial perfusion over a short period.

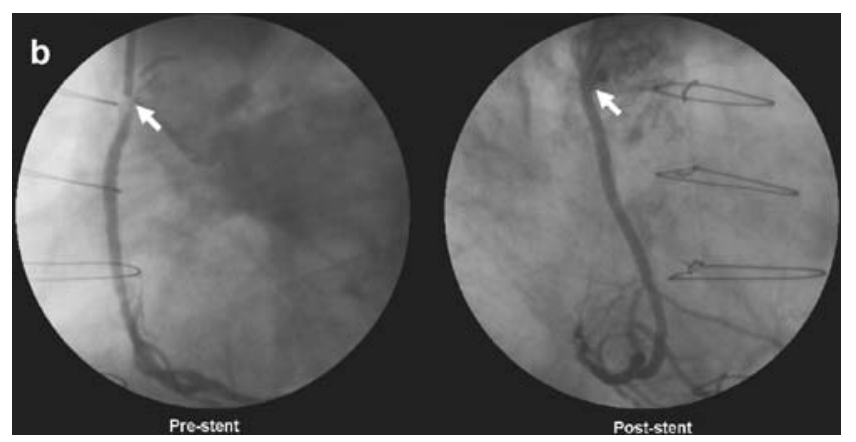

\section{References}

1. Emre A, Ersek B, Gursurer M, Aksoy M, Siber T, Engin O, et al. Angiographic and scintigraphic (perfusion and electrocardiogram gated SPECT) correlates of clinical presentation in unstable angina. Clin Cardiol 2000;23:495-500.

2. Heller GV, Stowers SA, Hendel RC, Herman SD, Daher E, Ahlberg AW, et al. Clinical value of acute rest technetium$99 \mathrm{~m}$ tetrofosmin tomographic myocardial perfusion imaging in patients with acute chest pain and nondiagnostic electrocardiograms. J Am Coll Cardiol 1998;31:1011-7. 